\title{
Pendekatan Regionalisme dalam Redesain Museum Majapahit
}

\author{
Riza Aisyah dan Rullan Nirwansjah \\ Departemen Arsitektur, Fakultas Arsitektur, Desain, dan Perencanaan, \\ Institut Teknologi Sepuluh Nopember (ITS) \\ e-mail: rullan@arch.its.ac.id
}

\begin{abstract}
Abstrak-Pada perancangan museum yang moderen namun memiliki aspek kedaerahan, pendekatan yang paling tepat untuk digunakan adalah pendekatan regionalisme. Menurut William Curtis, Regionalisme diharapkan dapat menghasilkan bangunan yang bersifat abadi, melebur atau menyatu antara yang lama dan yang baru, antara regional dan universal. Pendekatan Regionalisme dalam redesain Museum Majapahit di Trowulan dilakukan dengan metode transformasi melalui strategi peminjaman (borrowing). Lokasi museum ini berada di Jawa, sehingga rumah adat Jawa yaitu joglo dipilih untuk ditransformasikan untuk diterapkan pada penataan massa dan zoning museum. Sementara itu, transformasi pada Candi Bajang Ratu diterapkan pada perancangan bentuk dari Museum ini untuk mempertahankan ciri khas dari Kerajaan Majapahit.
\end{abstract}

Kata Kunci-Museum, Regionalisme, Transformasi, Joglo, Majapahit, Candi, Bajang Ratu, Trowulan, Mojokerto

\section{PENDAHULUAN}

$\mathrm{R}$ EGIONALISME dalam arsitektur merupakan suatu gerakan dalam arsitektur yang menganjurkan penampilan bangunan yang merupakan hasil senyawa dari internasionalisme dengan pola kultural dan teknologi modern dengan akar, tata nilai dan nuansa tradisi yang masih di anut oleh masyarakat setempat [1].

Konsep regionalisme diperkirakan berkembang sekitar tahun 1960 [2]. Sebagai salah satu perkembangan arsitektur modern yang mempunyai perhatian besar pada ciri kedaerahan. Aliran pemikiran ini tumbuh terutama di negara berkembang. Ciri kedaerahan yang dimaksud pada arsitektur regionalisme berkaitan erat dengan budaya setempat, iklim, dan teknologi pada saatnya (Ozkan, 1985) [3][4].

Menurut William Curtis, Regionalisme diharapkan dapat menghasilkan bangunan yang bersifat abadi, melebur atau menyatu antara yang lama dan yang baru, antara regional dan universal [5]. Kenzo Tange menjelaskan bahwa Regionalisme selalu melihat ke belakang, tetapi tidak sekedar menggunakan karakteristik regional untuk mendekor tampak bangunan [3]. Arsitektur Tradisional mempunyai lingkup regional sedangkan Arsitektur Modern mempunyai lingkup universal. Dengan demikian maka yang menjadi ciri utama regionalisme adalah menyatunya Arsitektur Tradisional dan Arsitektur Modern [3].

Suha Ozkan membagi Regionalisme menjadi dua bagian, yang pertama adalah concrete regionalism yang meliputi seluruh pendekatan kepada ekspresi daerah/regional dengan mencontoh kehebatannya, bagian-bagiannya, atau seluruh bangunan di daerah tersebut. Apabila bangunan-bangunan tadi sarat dengan nilai spiritual maupun perlambang yang sesuai, bangunan tersebut akan lebih dapat diterima di dalam bentuknya yang baru dengan memperlihatkan nilai-nilai yang melekat pada bentuk aslinya. Hal lain yang penting adalah mempertahankan kenyamanan pada bangunan baru, ditunjang oleh kualitas bangunan lama. Bagian kedua yaitu Abstract Regionalism yang menggabungkan unsur-unsur kualitas abstrak bangunan, misalnya massa, solid dan void, proporsi , sense of space, pencahayaan, dan prinsip-prinsip struktur dalam bentuk yang diolah kembali. ${ }^{[4]}$

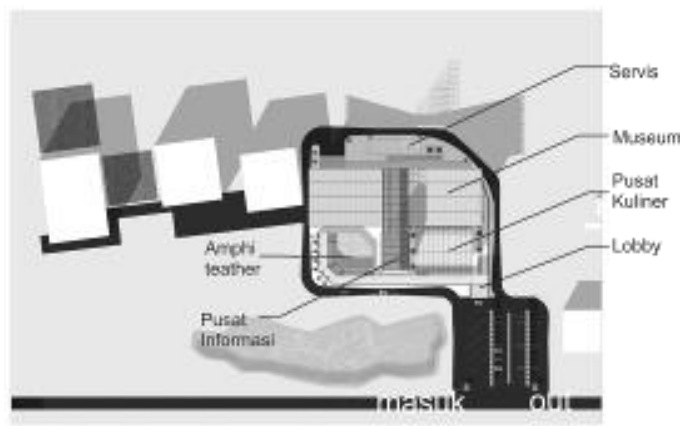

Gambar 1. Site Plan

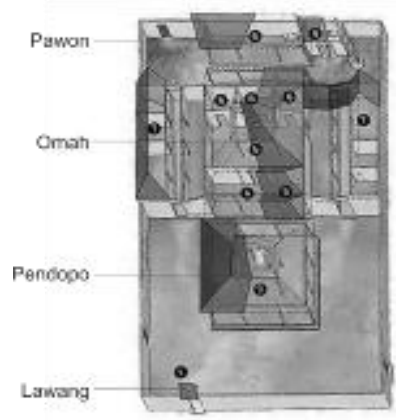

Gambar 2. Tatanan Massa Joglo
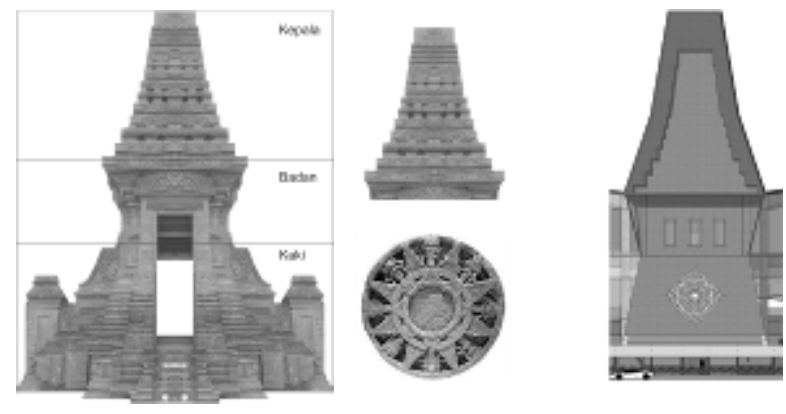

Gambar 3. Transformasi Candi Bajang Ratu. 
Terdapat dua pola utama dalam taxonomi arsitektur regionalisme yaitu pola derivatif dan pola transformatif. Pola derivativ sebenarnya meniru atau memelihara bentuk arsitektur tradisi atau vernakular, untuk fungsi bangunan baru atau moderen. Sementara itu pada arsitektur regional yang bersifat transformatif, bangunan baru tidak lagi sekedar meniru bangunan lama. Tetapi berusaha mencari bentuk-bentuk baru, dengan titik tolak ekspresi bangunan lama baik yang bersifat replikatif maupun abstrak [3].

Di Indonesia, kebudayaan yang paling berpengaruh pada pembentukan identitas bangsa Indonesia dan landasan Negara Indonesia adalah kebudayaan dari Kerajaan Majapahit. Semboyan negara kita yaitu Bhineka Tunggal Ika, juga diambil dari kitab peninggalan Majapahit yaitu kitab Sutasuma karangan Mpu Tantular. Maka dari itu penting bagi kita untuk melestarikan kebudayaan peninggalan Kerajaan Majapahit.

Museum Majapahit merupakan museum yang menyimpan peninggalan Kerjaan Majapahit. Museum ini juga terletak di Trowulan yang diyakini sebagai pusat pemerintahan Kerajaan Majapahit pada zamannya, karena banyak ditemukan candi dan peninggalan lain dari Kerajaan Majapahit pada kawasan ini. Namun fasilitas pada museum ini belum memadai dilihat dari banyaknya peninggalan yang tercecer serta kondisi lain yang menyebabkan museum ini kurang menarik. Data pengunjung pada tahun 2016 juga menunjukkan penuruna pengunjung yang terjadi di setiap bulan.

Redesain Museum Majapahit melalui pendekatan regionalisme diharapkan mampu melengkapi kekurangan fasilitas serta menghidupkan museum ini dengan tetap memiliki aspek kedaerahan dan kearifan lokal dari zaman Majaphit. Sehingga generasi selanjutnya dapat mempelajari dan mengetahui kemegahan kerajaan terbesar di Nusantara ini.

\section{METODA PERANCANGAN}

Di dalam proses merancang suatu objek melalui pendekatan regionalisme, terdapat berbagai macam cara untuk memulai proses merancang, salah satu cara yang di gunakan adalah transformasi. Transformasi dapat diartikan sebagai proses perubahan bentuk dimana bentuknya mencapai tahap akhir dengan menanggapi keragaman dinamika eksternal dan internal. Menrut Josef Prijotomo, apabila di Indonesiakan kata transformasi dapat disepadankan dengan kata pemalihan, yang artinya perubahan dari benda asal menjadi benda jadiannya.

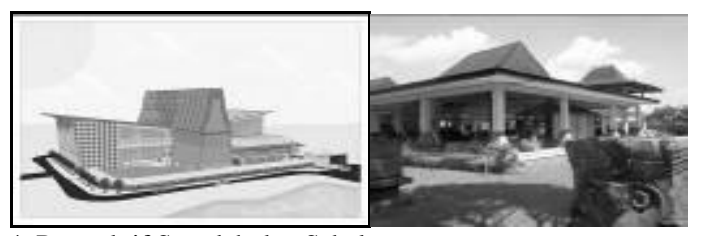

Gambar 4. Prespektif Sesudah dan Sebelum.

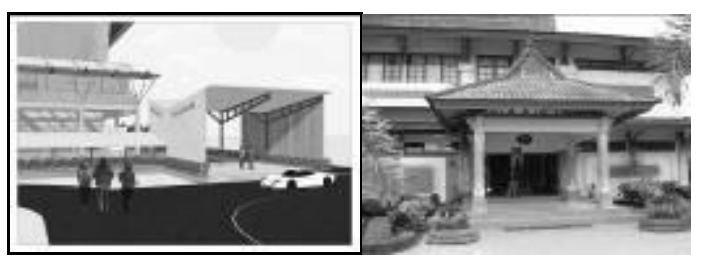

Gambar 5. Enterance Sesudah dan Sebelum.

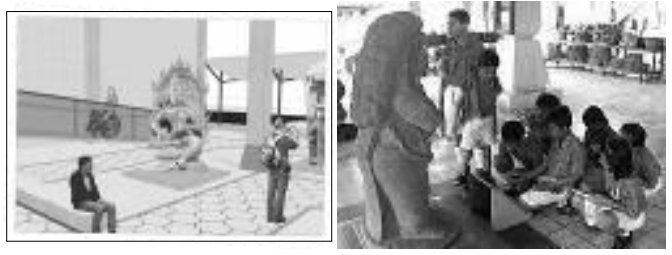

Gambar 6. Suasana Museum Sesudah dan Sebelum.

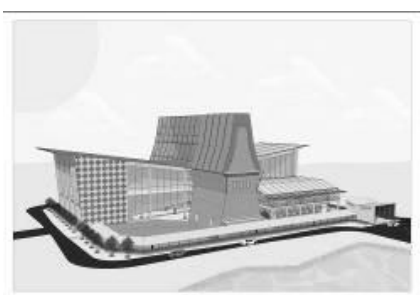

Gambar 7. Prespektif Museum.

Baik perubahan yang sudah tidak memiliki atau memperlihatkan kesamaan atau keserupaan dengan benda asalnya, maupun perubahan yang benda jadiannya masih menunjukan petunjuk benda asalnya.

Terdapat 3 strategi dalam melakukan transformasi bentuk, yang pertama adalah strategi tradisional sebagai evolusi progresif dari sebuah bentuk melalui penyesuaian langkah demi langkah terhadap batasan-batasan eksternal, internal dan artistic. Yang kedua adalah dengan peminjaman dari objekobjek lain dan mempelajari sifat dua dan tiga dimensinya sambil terus menerus mencari kedalaman interpretasi dengan memperhatikan kelayakan aplikasi dan validitasnya. Transformasi peminjaman ini adalah pemindahan rupa dan dapat pula dikualifikasikan sebagai metafora rupa. Strategi terakhir adalah dekonstruksi atau dekomposisi, yaitu sebuah proses dimana susunan yang ada dipisahkan untuk mencari cara baru dalam kombinasinya dan menimbulkan sebuah kesatuan baru dan tatanan baru dengan strategi struktural dan komposisi yang berbeda [6].

Dalam perancangan ulang museum majapahit ini, strategi yang digunakan adalah peminjaman (borrowing) dan objek yang ditransformasikan adalah Candi Bajang Ratu, salah satu candi peninggalan Kerajaan Majapahit. Candi Bajang Ratu dipilih karena fungsinya sebagai gerbang menuju keraton, hal ini sesuai dengan salah satu fungsi museum ini yaitu pusat informasi yang seakan menjadi gerbang bagi pengunjung sebelum menuju ke museum maupun situs lain di kawasan Trowulan.

Selain itu, pendekatan regionalisme dalam penataan massa dan zoning dilakuakan dengan mentransformasi pola tata letak dari Joglo (rumah adat jawa) untuk diterapkan pada redesain museum majapahit ini. Joglo yang merupakan rumah adat dari Jawa dipilih karena letak museum ini yang juga berada di Pulau Jawa.

\section{HASIL DAN EKSPLORASI}

\section{A. Konsep Zoning dan Tatanan Massa}

Museum ini terletak di Trowulan, kota Mojokerto, Jawa Timur. Maka dari itu, tatanan massa pada perancangan museum ini mentransformasikan denah dan tatanan massa dari 
Joglo yang merupakan rumah adat Jawa. Bagian-bagian ruang dari rumah Joglo diterjemahkan kedalam perancangan museum dengan mencari kesepadanan sifat dan fungsinya dengan bagian-bagian ruang pada museum. Pada bangunan ini, peletakan lawang ditransformasikan menjadi lobby. Fungsi lawang yaitu gerbang berkesuaian dengan fungsi lobby yaitu sebagai bagian bangunan yang pertama kali dilalui. Pendopo pada Joglo ditransformasikan menjadi pusat informasi. Fungsi pendopo yaitu untuk menerima tamu, berkesuaian dengan fungsi pusat informasi sebagai tempat menerima pengunjung atau wisatawan sebelum berkunjung ke situs lain di kawasan trowulan. Peletakan omah ditransformasikan menjadi bangunan fasilitas utama yaitu museum, sesuai fungsi omah yang merupakan bangunan utama. Sementara Pawon pada Joglo ditransformasikan menjadi bangunan servis sesuai dengan fungsi dapur sebagai fasilitas servis pada sebuah rumah.

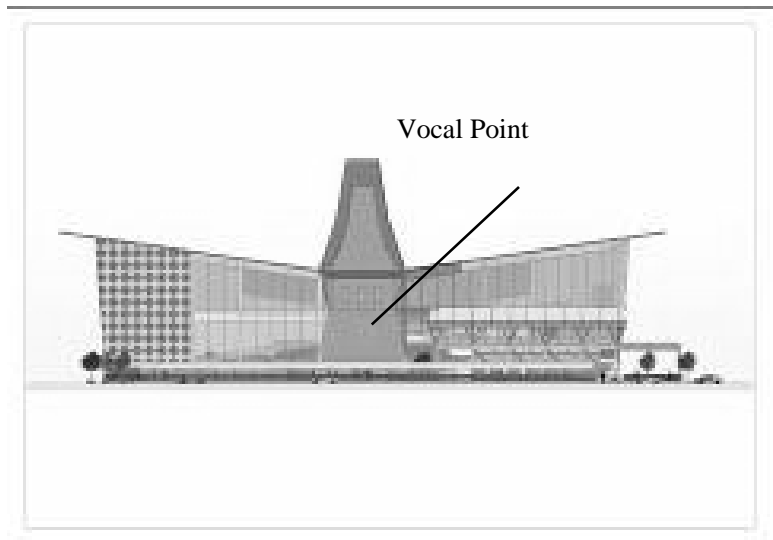

Gambar 8. Tampak Timur.

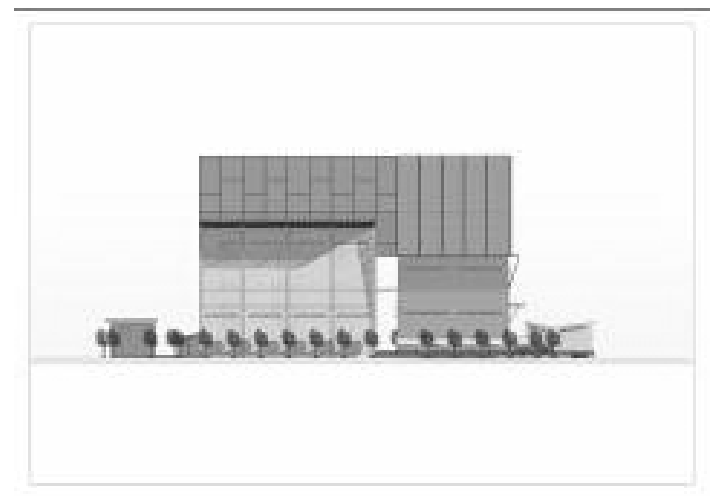

Gambar 9. Tampak Selatan.

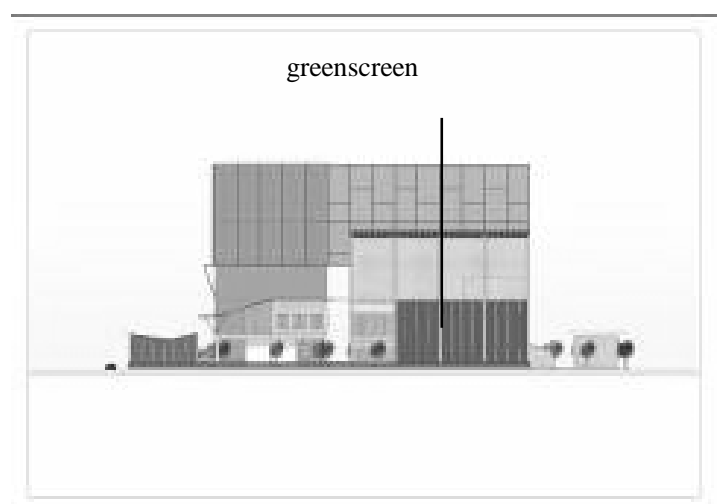

Gambar 10. Tampak Utara.

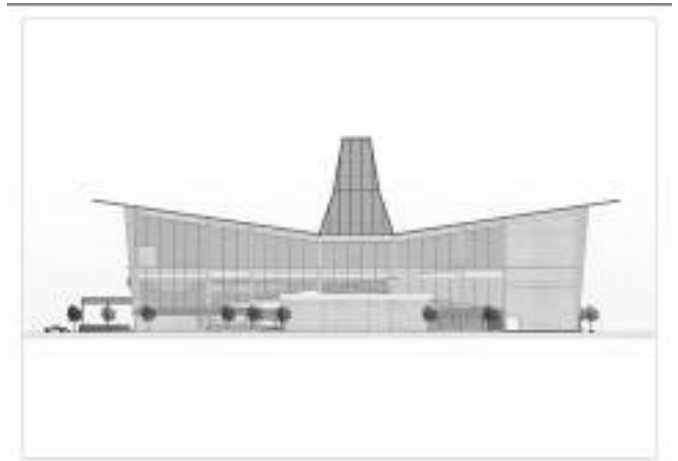

Gambar 11. Tampak Barat

\section{B. Konsep Bentuk}

Candi di Jawa timur cenderung memiliki bentuk yang ramping, begitu juga bentuk candi Bajang Ratu. Maka dari itu pada perancangan museum yang luas, transformasi bentuk candi bajang ratu dilakukan pada vocal point dari bangunan ini, sehingga tetap mampu mepertahankan bentuk ramping dari candi Bajang Ratu. Transformasi diterapkan pada bangunan pusat informasi Majapahit karena sifatnya yang seakan menjadi gerbang bagi pengunjung dan wisatawan sebelum menuju ke museum maupun situs lain di kawasan Trowulan, hal ini berkesuaian dengan fungsi candi Bajang Ratu yaitu sebagai salah satu gerbang menuju ke keraton Majapahit.

Proses transformasi pada rancangan ini dilakukan dengan membagi candi menjadi 3 bagian, yaitu kepala, badan, dan kaki. Dari pembagian ini kemudian ditemukan ratio dari masing-masing bagiannya yaitu 2:1:2, selanjutnya perbandingan ini tetap dipertahankan sebagai acuan dalam transformasi bentuk yang dilakukan. Tujuan dari pencarian ratio ini agar hasil transformasi tetap memiliki kesesuaian bentuk dengan candi Bajang Ratu. Selain itu, sifat void dari candi Bajang Ratu juga tetap dipertahankan untuk mempertahankan ciri khas dari Candi Majapahit.

Dalam perancangan museum ini, salah satu material yang dipakai adalah bata merah. Penggunaan material ini sangat berkesesuaian dengan pendekatan regionalisme, karena daerah Trowulan merupakan daerah penghasil bata merah. Terlebih lagi, bata merah juga merupakan material dari Candi Bajang Ratu ini.

\section{Konsep Sirkulasi}

Dalam perancangan Museum, salah satu aspek yang penting adalah sirkulasi. Pada museum ini, tatanan massa membuat pengunjung harus melalui pusat informasi terlebih dahulu sebelum menuju ke museum. Selanjutnya, setelah mengunjungi museum, jalan keluar pengunjung diarahkan melalui toko souvenir, sehingga menjaga keberlangsungan penjualan. Dari toko souvenir ini, barulah pengunjung keluar melewati pusat kuliner. Namun, untuk menuju ke pusat kuliner dan juga amphitheater, pengunjung bisa langsung menuju kesana dari lobby tanpa perlu melewati pusat informasi terlebih dahulu. Terdapat beberapa sirkulasi dalam penataan benda pajang dalam museum yaitu radial plan, random plan, direct plan, dan open plan [7]. Masing-masing dari pola sirkulasi ini memiliki kekurangan dan kelebihan masing-masing, seperti 
pola sirkulasi langsung yang sangat sederhana dan hanya memberikan pilihan jalan yang terbatas kepada pengunjung. Berbeda dengan pola acak, pola sirkulasi ini memberikan ragam alternatif arah yang membuat pengunjung-pengunjung seakan-akan tidak terkontrol. Pola sirkulasi terbuka sangat baik digunakan jika perancang ingin agar pengunjung dapat melihat keseluruhan pameran secara langsung seperti ruang pamer lukisan, misalnya. Walaupun kekurangannya adalah pengunjung kehilangan rasa keingintahuan dan eksplorasi karena semua benda pamer sudah terlihat [8].

Sirkulasi benda pajang pada museum ini menggunakan sirkulasi radial. Pengunjung diarahkan melalui penataan benda dan pola lantai sehingga melewati dan melihat seluruh koleksi dari museum ini.

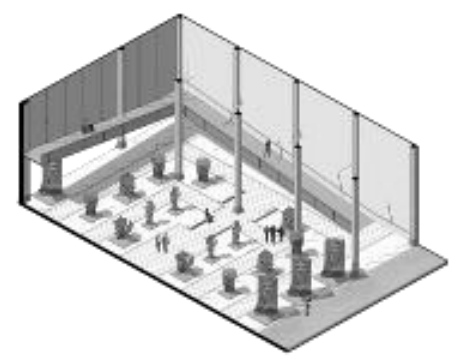

Gambar 12. Interior Museum.

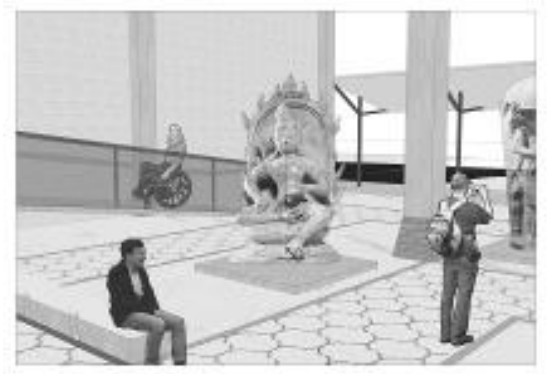

Gambar 13. Interior Museum.

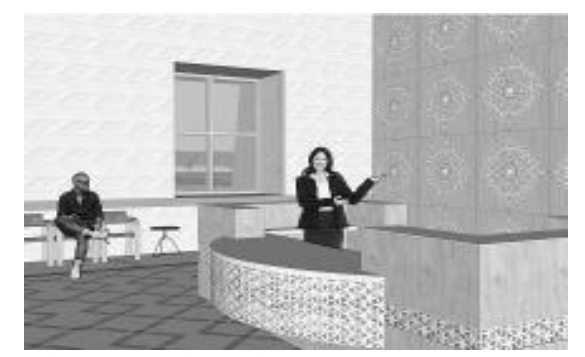

Gambar 14. Interior Pusat Informasi

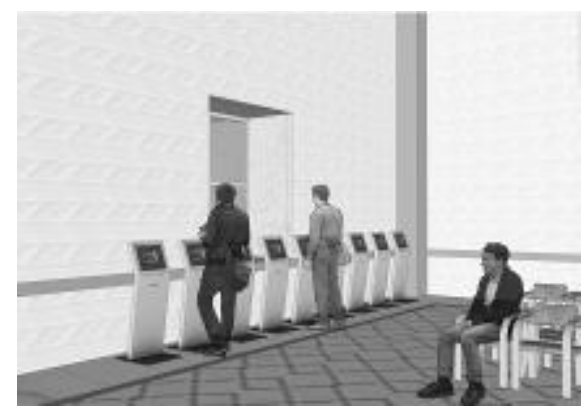

Gambar 15. Interior Pusat Informasi.

\section{Konsep Pendingin Pasif}

Museum Majapahit sebelumnya memiliki konsep terbuka atau semi-outdoor terlihat dari bentuk bangunan yang terdiri dari 4 naungan berupa pendopo. Pada perancangan museum yang baru, konsep museum terbuka ini tetap dipertahankan pada lantai 1. Konsep ini dapat tetap dipertahankan karena benda koleksi dari museum Majaphit sebagian besar terdiri dari patung batu besar yang memiliki ketahanan terhadap suhu dan cahaya yang tinggi. Sementara benda koleksi yang memiliki ketahanan rendah seperti keramik dan perhiasan diletakkan di lantai 2 yang menggunakan pendingin aktif dan pencahayaan buatan, sehingga suhu dan cahaya dapat diatur sesuai kebutuhan.

Pada lokasi museum, angin berhembus dari utara ke selatan sehingga membawa hawa panas, karena pada lokasi ini matahari dominan berasal dari utara, maka dari itu bangunan ini menggunakan greenscreen pada bagian utara agar udara yang masuk ke bangunan menjadi lebih dingin. Sementara itu, pada bagian timur bangunan juga terdapat danau kecil yang juga bisa difungsikan sebagai pendingin suhu.

\section{E. Konsep Struktur dan Utilitas}

Redesain pada perancangan ini dilakukan dengan tetap memanfaatkan beberapa struktur dari bangunan yang telah ada sebelumnya. Struktur yang telah ada ini juga berperan dalam proses transformasi bentuk yang terjadi, karena bentukan baru dibuat dengan penyesuaian terhadap struktur bangunan lama.

Pada perancangan utilitas untuk kebakaran, aspek regional lain yang dimanfaatkan adalah adanya danau kecil di kompleks museum ini. Danau ini pada musim hujan dapat dijadikan drainase sekaligus penampungan air. Air yang ditampung ini nantinya bisa digunakan sebagai sumber air untuk water sprinkler pada saat terjadinya kebakaran.

\section{KESIMPULAN}

Regionalisme pada perancangan museum ini dilakukan dengan metode transformasi melalui strategi peminjaman (borrowing). Penerapan pendekatan regionalisme melalui metode transformasi terlihat jelas pada tatanan massa dan denah joglo yang bagian-bagiannya ditransformasikan sesuai sifat dan fungsinya hingga dapat diterapkan pada perancangan museum. Selain itu, bentuk vocal point pada perancangan ini juga merupakan hasil transformasi dari candi Bajang Ratu. Pemanfaatan aspek regionalisme lain seperti arah angin berhembus untuk pendingin pasif bangunan dan penggunaan material dari daerah sekitar yaitu bata merah juga merupakan penerapan pendekatan Regioalisme dalam perancangan ini.

\section{UCAPAN TERIMA KASIH}

Ucapan terima kasih yang sebesar-besarnya kepada pihakpihak yang telah membantu di dalam pembuatan jurnal studi ini. Terimakasih atas bantuan dan berbagai informasi yang telah diberikan oleh pihak Museum Majapahit di Trowulan, Kota Mojokerto. Ucapan terimakasih juga ditujukan pada jurusan Arsitektur Institut Teknologi Sepuluh Nopember Surabaya yang mendukung pembuatan jurnal studi ini. 


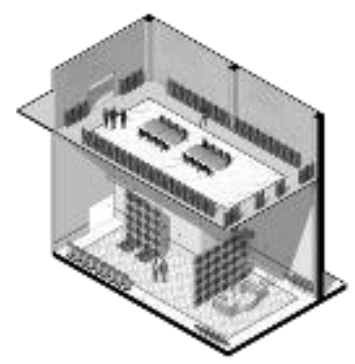

Gambar 16. Interior Pusat Informasi.

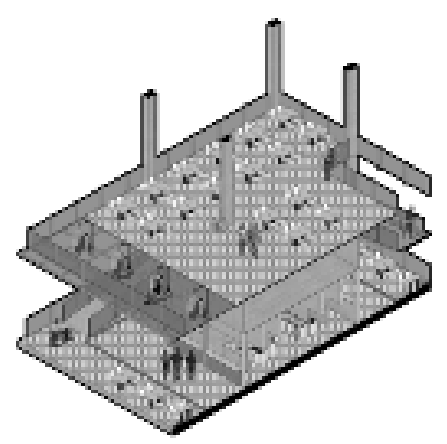

Gambar 17. Interior Pusat Kuliner.

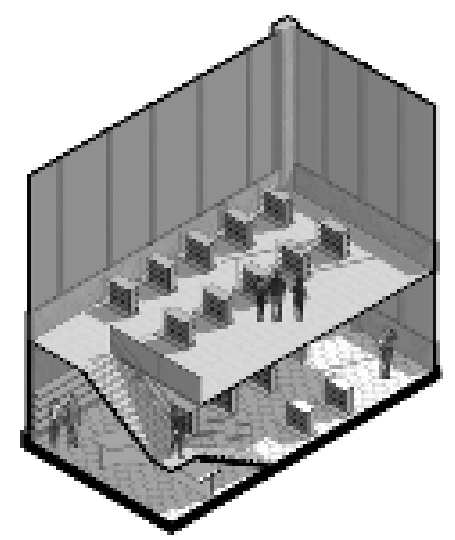

Gambar 18. Interior Toko Souvenir.

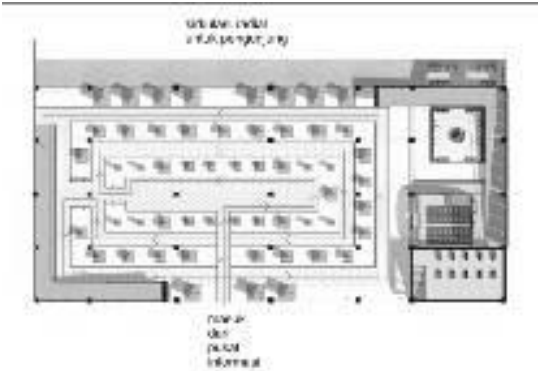

Gambar 19. Sirkulasi Bangunan.

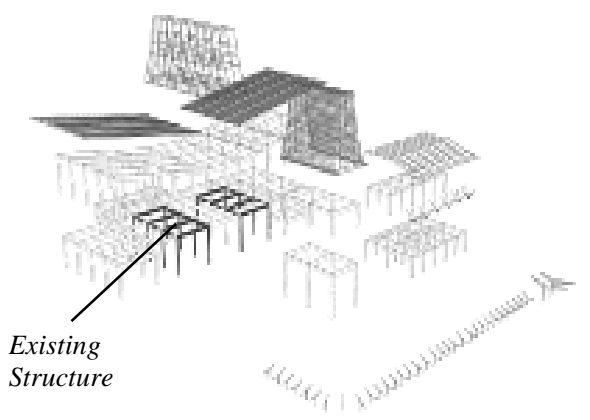

Gambar 20. Aksonometri Struktur.

\section{DAFTAR PUSTAKA}

[1] J. Heng, "Landasan Konseptual Perencanaan Dan Perancangan Pusat Pengembangan Kebudayaan Tradisional Tionghoa Peranakan Di Batam," 2015.

[2] C. Jencks, The Language of Post-Modern Architecture. Rizzoli, 1977.

[3] A. Dharma, "Aplikasi Regionalisme Dalam Desain Arsitektur," 2014.

[4] S. Ozkan, "Regionalism within Modernism," Sp. Free., 1989.

[5] W. J. R. Curtis, Towards an Authentic Regionalism. Singapore: Concept Media Ltd, 1968.

[6] A. C. Antoniades, Poetics of Architecture: Theory of Design. New York: Van Nostrand Reinhold, 1990.

[7] B. Hansen, Great Exhibits!: An Exhibit Planning and Construction Handbook for Small Museums. Maryland: Rowman \& Littlefield, 2017.

[8] A. A. A. Wulandari, "Dasar-Dasar Perencanaan Interior Museum," Humaniora, vol. 5, no. 1, pp. 246-257, 2014. 